\title{
Análisis de los catálogos de las editoriales independientes bogotanas y cordobesas, enfocadas en la edición infantil y juvenil 2012-2017*
}

Fecha de recepción: 08 de septiembre de 2018

Fecha de aprobación: 30 de marzo de 2019

\section{Resumen}

El artículo socializa los resultados parciales que surgen del análisis y la revisión de los catálogos de las editoriales independientes bogotanas (Colombia) y cordobesas (Argentina), que realizan publicaciones orientadas a un público infantil y juvenil. Esto se acompaña, a modo de contexto, de una problematización que ha traído consigo la influencia de políticas públicas en temas sobre promoción de lectura coincidente con el florecimiento de editoriales independientes en toda la región en el subsector editorial infantil y juvenil. Metodológicamente, con una estrategia comparativa, se cotejaron los catálogos y las implicaciones de estos dispositivos en una ventana de observación de cinco años. Se revisaron variables como la unidad interna del sistema, la congruencia conversacional de los textos, la pertinencia al contexto, los géneros recurrentes, su apuesta frente al mercado, la estética y poética, y el diseño editorial. Esto se complementó con entrevistas semiestructuradas con los editores, que permitieron discutir lo observado.

Palabras clave: editoriales independientes, edición infantil y juvenil, catálogo editorial, diseño editorial, edición en América Latina.

Citar: Castellanos, A., Maina, M.G. (julio- diciembre de 2019). Análisis de los catálogos de las editoriales independientes bogotanas y cordobesas, enfocadas en la edición infantil y juvenil 2012-2017. La Palabra, (35), 43-52. Goi https://doi. org/10.19053/01218530.n35.2019.8404

\begin{abstract}
Alexis Castellanos Escobar
Pontificia Universidad Javeriana Doctorando en Estudios Sociales de América Latina de la Universidad Nacional de Córdoba en Argentina. Magíster en Comunicación de la Pontificia Universidad Javeriana. Diseñador Gráfico de la Universidad Nacional de Colombia. Profesor Asistente del Departamento de Comunicación de la Pontificia Universidad Javeriana (Bogotá, Colombia). Đhttps://orcid.org/0000-0003-07573672
\end{abstract}

alexis.castellanos@javeriana.edu.co

\section{Melisa Gisela Maina}

Universidad Nacional de Córdoba Doctoranda en Estudios Sociales de América Latina de la Universidad Nacional de Córdoba en Argentina. Becaria Doctoral CONICET. Técnica correctora literaria y Licenciada en Letras Modernas en la misma institución. Profesora adscripta de Metodología de la Investigación en Ciencias Sociales. Dhttps://orcid. org/0000-0002-9738-9491

melisa.maina@gmail.com

* Artículo de investigación proveniente del proyecto "Voces de la producción editorial bogotana y cordobesa. Estudio de caracterización de los catálogos editoriales y las publicaciones realizadas entre 2012 y 2017 '. 


\section{la palabra}

\section{Catalogues' Analysis of the Independent Publishing Houses in Bogota and Cordoba, Focusing on Children's and young people's issued from 2012-2017.}

\section{Abstract}

This paper discusses the partial results that arise from the analysis and revision of the catalogues of the independent publishing houses of Bogotá (Colombia) and Córdoba (Argentina) which publications are aimed at children and young people. This is accompanied, as a context by a problematization that has brought with the influence of public policies on issues in reading promotion synchronized with the flourishing of independent publishers throughout the region in the children's and youth publishing subsector. Methodologically, with a comparative strategy, the catalogues and the implications of these devices were compared in a five-year observation window. We reviewed variables such as the internal unity of the system, the conversational congruence of texts, the relevance to the context, the recurrent genres, their commitment to the market, aesthetics and poetics, and editorial design. This was complemented with semi-structured interviews with the editors, which allowed for a discussion of what was observed.

Key words: independent publishing houses, children's and youth edition, editorial catalogue, editorial design, edition in Latin America.

\section{Introducción}

A excepción de los que se hacen para idiotizar, cada libro contiene el fragmento de un plano del tesoro (o al menos así se decía antes). Sólo cuando reunamos todos los pedazos seremos capaces de descifrar ese secreto que parece tan bien guardado. A veces uno se toma su tiempo. No es raro empezar a leer a los 7 años y ver que a los 77 seguimos con el mismo libro entre las manos.

(Editorial Media Vaca)

Acometer una revisión analítica de los catálogos construidos por editoriales independientes en países periféricos, resulta una «quijotada» en el buen sentido de la palabra. Pues, recoge el entusiasmo de una serie de emprendedores del sector cultural, que hacen del libro su principal producto y protagonista. En tiempos en que el sector editorial evidencia cambios y mutabilidades, propias de una industria móvil -nunca ha sido fija-, lo «alternativo» o «independiente», cada vez persigue abrirse espacio entre los grandes conglomerados del negocio. En una especie de lucha entre el pez grande y el chico, la supervi- 
vencia de apuestas marginales, con proyectos editoriales de calidad, que se esfuerzan por evidenciar diferenciales y valor agregado en su producto, es cada vez mayor.

Por lo tanto, este trabajo nace con el ambicioso objetivo de construir una cartografía de las editoriales independientes que dedican sus esfuerzos a la producción de contenidos dirigidos a públicos infantiles y juveniles, lo que se convierte en un desafío, dado los múltiples fragmentos dispersos de la trama cultural y propios de América Latina. La apuesta teórica de los estudios editoriales en nuestra región, carece de constructos epistemológicos propios, dada la pervivencia de una hegemonía cultural y la influencia de los investigadores, consultores $\mathrm{y}$ asesores en la industria del libro provenientes de España, Francia, Inglaterra, Estados Unidos, entre otros. Estos discursos han sido fundamentales para alentar el desarrollo de aparatos teóricos y conceptuales que puedan ser de utilidad para examinar los heterogéneos fenómenos relacionados con las editoriales y su producción.

A nivel regional, México, Brasil y Argentina lideran esfuerzos en el análisis y seguimiento del campo y de la industria editorial, pero en Colombia aún las propuestas son estudios de caracterización generalistas e históricos que tienen dificultades para dar cuenta de las dinámicas que surgen al interior de las editoriales en nuestro contexto. Así las cosas, comprendemos que no es posible entender la industria editorial desde un solo paradigma, sino que se requiere una doble mirada: una culturalista, que imbrique las prácticas y procesos de producción de sentido y significación; y una economicista, que reconozca la tradición de un mercado y una industria alrededor del libro y las publicaciones, que por supuesto está atravesada por relaciones de fuerzas de larga data y coyunturas que afrontan los países.

Lo anterior, también dibuja una definición de editor como «mediador» entre autor y lector desde una perspectiva cultural y simbólica, o como «estratega» desde el enfoque económico, donde priman las habilidades de gestión y mercadeo, para sobrevivir en esta compleja industria. Esto genera por supuesto ciertas opacidades ideológicas en sus decisiones editoriales y una no neutralidad en la configuración del catálogo de la editorial, lo que condicionará otro tipo de variables dentro de cualquier proyecto en la industria de las publicaciones.

Para el caso del mercado del libro infantil y juvenil en Latinoamérica, su no estaticidad es parte constitutiva de su oferta, pese a las heterogéneas crisis de la industria editorial, pequeñas empresas de edición han podido sortear, con creatividad y escaso presupuesto, las dificultades financieras. A su vez, a modo de fenómeno general, en América Latina se reconfiguró el mapa de la lectura y escritura, generando cruces e interrelaciones a partir de los planes nacionales de lectura. Esto ha generado transacciones comerciales importantes que principalmente han beneficiado a los grupos editoriales transnacionales.

Finalmente, entonces, lo que discutiremos en una primera medida serán en líneas generales las repercusiones de la política pública, así como las resonancias de los planes de lectura colombiano y argentino. Seguidamente, revisaremos de forma contextual el fenómeno de editoriales «independientes» en Latinoamérica, para dar paso a una reflexión sobre la formulación de los catálogos editoriales, en tanto dispositivos culturales y económicos. Posteriormente, daremos claridad sobre el abordaje metodológico, los resultados y conclusiones que se tienen de avance de este proyecto comparativo.

Política pública y planes de lectura: circuito comercial del libro

A partir de una mirada contextual, en los últimos años se ha reconfigurado el mapa de la lectura y la escritura en América Latina. Libros, lectura y lec- 
tores han estado relacionados con procesos de democracia y la libertad de una nación. La pugna por una medición de los consumos culturales, se observa en la concreción y elaboración de políticas públicas de lectura, muchos de ellos a través de planes nacionales y campañas de lectura. Por ejemplo, en 2006, se creó la Red Regional de Responsables de Políticas y Planes Nacionales de Lectura (REDPLANES), colectivo de entidades y personas que comparten el interés sobre las diferentes aristas de los planes nacionales de lectura.

Según estos estudios, los planes y programas de lectura se han multiplicado en la región, guardando el ideal que se afinquen en el centro de las políticas públicas de los Estados. Si bien, algunos países desarrollaron planes y programas en la década de 1990, es a partir del año 2000 que encontramos un reporte de acciones que tienen estatus de planes de lectura en diez países de la región. Particularmente, las editoriales independientes analizadas surgen en esta época. Esto implica revisar una serie de situaciones con relación a la problemática de la conformación de «una región de lectores» en pleno proceso político y cultural. Una propuesta que se hace desde el Centro Regional para el Fomento del Libro en América Latina y el Caribe (CERLALC) para aunar esfuerzos de establecer relaciones entre diversos países.

Estas políticas públicas de promoción a la lectura también activan una serie de movimientos en relación al libro. Así, el círculo de producción y circulación se ha visto modificado por el impulso generado en los últimos años. Ese impulso ha modificado el campo cultural, lo que se evidencia al analizar los catálogos de editoriales independientes de Córdoba (Argentina) y Bogotá (Colombia) y su acercamiento a la comprensión de numerosas variables de análisis, lo cual implica revisar de qué forma las políticas han impactado en su gestación y mantenimiento dentro del campo cultural.

La clara incentivación al mercado producida por la fuerte demanda de políticas públicas de promoción a la lectura, produjo un fenómeno con diferentes luces y matices. Por un lado, puede observarse un incremento en la producción editorial con una apuesta de calidad; y, por otro, una carrera mercantilista de la novedad. Las editoriales independientes surgen en esa paradoja y debieron resolver ciertas impaciencias del sistema financiero. Para el caso Argentina del objetivo del Plan Nacional de Lectura es "Fortalecer la lectura y escritura como condiciones básicas de la educación para la educación a largo de toda la vida, la construcción de una ciudadanía responsable y la libre circulación del conocimiento" (Ley de Educación Nacional 26.606). Encontramos una concepción de la lectura como herramienta indispensable para la formación integral del individuo y que es función del Estado garantizar el derecho a la lectura y acceso al libro en todos los niveles sociales. En esa garantía de acceso libre a todos, el Estado se convierte en un ente regulador de la economía de los ecosistemas culturales, en este caso del libro.

A su vez, en el caso colombiano el Plan Nacional de Lectura, «Leer es mi cuento» tiene un objetivo cuantitativo: "[...] un país de lectores incrementando los índices de lectura de 1,9 a 3,2 libros leídos por habitante". Uno de los principales objetivos es:

\footnotetext{
Garantizar el acceso a la cultura escrita, la circulación de los materiales de lectura y promover la obra de autores locales son los propósitos de este componente del Plan Municipal de Lectura como una forma de contribuir a la producción local literaria y a la interacción de todos los actores del universo del libro en la ciudad (Zapata, 2014, p. 77.).
}

Lo que evidencia la intención de convertir a Colombia en un gran centro editorial, para que compita en el mercado internacional aumentando las exporta- 
ciones de libros colombianos. Podemos, entonces, percibir una fuerte apuesta por el incentivo económico y cultural hacia la industria editorial. Esto provoca modificaciones del sistema literario en el plano financiero, pues las políticas públicas estimulan la producción a nivel local, pero también compran a grandes empresas internacionales, conglomerados que están muy bien constituidos y que normalmente terminan acaparando gran parte de las compras que realiza el Estado. Si bien se activan circuitos económicos, a veces no son suficientes para mantener vigentes las pequeñas editoriales. Asimismo, y no es un tema menor, el recorte presupuestal y desfinanciamiento de programas que incentiven la promoción y el fomento a la lectura.

Editoriales independientes: un fenómeno en crecimiento en América Latina

El ecosistema de editoriales en nuestra región, en una apuesta ecológica, si bien es diverso sigue siendo mayoritariamente habitado por conglomerados $\mathrm{y}$ grupos transnacionales que absorbieron gran parte de la industria nacional. No obstante pese a esta situación, cada vez se ve un crecimiento en la conformación de iniciativas y proyectos editoriales, que buscan tener rasgos diferenciales en su oferta, que ha aumentado en los últimos años con el acce- so a procesos de producción de contenidos a través de software y herramientas tecnológicas, la incorporación de la impresión digital y la formación universitaria de profesionales que trabajan alrededor del libro y sus contenidos.

Según los registros documentales, hasta el 2003 no había una fuerte producción de libros álbumes en Argentina (Schritter, 2005; Menéndez, 2006; Bajour y Carranza, 2003). Los ejemplares que se conocían eran traídos de México y España. En ese mismo año, Cecilia Bajour comienza un artículo en la revista Imaginaria hablando de una ausencia, no solo de la escasa producción de libros álbumes, sino también de un preferencia del texto sobre la imagen: "La persistencia de este criterio puede explicar en parte la no edición de libros álbum en Argentina y, como consecuencia, la falta de incentivo para la producción y creación de este género por parte de escritores e ilustradores." (Bajour y Carranza). De esta manera, si bien la producción enfocada a los niños, niñas y jóvenes goza de una tradición importante por los textos escolares desde hace dos siglos (las cuales en muchos casos soportaron financieramente las editoriales), la concepción de consumidor que se afincó en el sistema capitalista, ha motivado el interés por productos editoriales orientados a estos públicos.
De esta forma, la editoriales independientes cordobesas que trabajan con literatura infantil, son: Comunicarte, creada en 1993, pero desde el 2004 con una fuerte apuesta a lo infantil y juvenil; Ediciones de la terraza, creada en 2012, su catálogo tiene preeminencia de libros ilustrados con una política de Creative Commons y un trabajo colectivo, que convoca a profesionales de diversas formaciones a través del trabajo por proyectos, deslocalizado.

Las editoriales independientes en Colombia, son: Cangrejo, fundada en 1993; Babel, fundada en 2005; también, en ese año, se crean Tragaluz y Taller de edición La Roca, que apuesta por una línea infantil y juvenil; Cohete, que surge en 2010; Cataplum, en 2016; y Siete Gatos, en 2017. Los años de inicio y expansión son coincidentes en algunos casos en Argentina y Colombia. Lo que implica revisar fenómenos económicos y culturales a nivel regional más que local.

\section{Catálogos de literatura infan- til y juvenil bogotanos y cor- dobeses}

De acuerdo con López y Malumián (2016), el “catálogo es la voz del editor y debe expresar una mirada sobre el mundo" (p. 24). Esto implica comprender la edición como un proceso de mediación cultural, que está atravesado por condiciones 
ideológicas, relaciones de poder, condiciones de producción y determinantes económicas. Estas tensiones de naturaleza tan diversa, terminan influyendo en las decisiones sobre la calidad y la rentabilidad de los productos editoriales. Por su parte, Zaid (2010) menciona que la importancia del catálogo editorial tiene que ver con lograr establecer vínculos y nexos entre los textos, así las cosas, "publicar un libro es ponerlo en el medio de una conversación" ( $\mathrm{p}$. 39). Lo anterior, da pistas para entender que el discurso (entendido como un conocimiento socialmente construido y un artefacto cultural) de la editorial se materializa a través del catálogo, pues allí se pueden ver sus acentos e intereses, los autores que privilegia, los públicos a los cuales les interesa llegar y el alcance de su producción.

Esta situación enfrenta al editor a una serie de decisiones que van más allá de la construcción operativa de un libro, y que tienen que ver con elementos de mercado, autonomía, tensiones financieras, aporte cultural y a la bibliodiversidad, así como la experticia en la gestión de proyectos editoriales. Esto sin contar las dificultades de la edición independiente en los países latinoamericanos, donde muchas veces los entornos no facilitan que estas iniciativas perduren a mediano y largo plazo.
Empero, las editoriales de literatura infantil han sabido construir catálogos que sobresalen en diseño y calidad. Las líneas gráficas cuidadas, un uso eficaz de colores, tipografías, imágenes, la distribución de las obras, hacen que se conviertan en un muestrario de diferentes perspectivas artísticas, creativas y editoriales. En general, se caracterizan por tener pocos libros editados en relación con las editoriales trasnacionales, pero cada libro tiene una historia particular, pues hay allí una serie de esfuerzos individuales y colectivos. La selección de autores e ilustradores constituye una estrategia que suele llevar largo tiempo, tanto como el proceso de edición e impresión, por todos los vericuetos que implica la manufactura. El principal objetivo apunta a la difusión de literatura infantil y juvenil de calidad, la cual comprenden haciendo un énfasis en el enfoque literario y despojándolo de la formación en valores o de la carrera mercantilista de la innovación.

\section{Metodología}

Con respecto a la metodología, nuestra apuesta se inscribe en el enfoque cualitativo, donde se privilegió el análisis descriptivo de documentos digitales y en papel, para relevar ejes de comparación entre las editoriales independientes de Argentina y Colombia. La presencia online a través de sitios web de la edi- torial, así como sus redes sociales, también se convirtieron en importantes fuentes de información para obtener datos. De esta forma, para la sistematización se diseñó un instrumento matriz que permitió recopilar los datos recogidos sobre las editoriales independientes bogotanas y cordobesas, que dedican parte de sus esfuerzos en proyectos orientados al público infantil y juvenil. La herramienta que se construyó contenía los siguientes ítems:

\section{a. Ciudad:}

Lugar donde funciona la editorial independiente y donde realiza sus actividades económicas y culturales.

\section{b. Nombre de la editorial:}

Nombre o razón social de la editorial.

\section{c. Año de fundación:}

Fecha de constitución de la editorial y a partir de la cual ha comenzado sus actividades.

\section{d. Número de catálogos:}

Número de catálogos con los que cuenta la editorial hasta al momento, y a través de los cuales promociona sus productos. 


\section{e. Soporte (impreso y/o di- gital):}

Tipo de soporte en el cual se encuentra el catálogo de la editorial, ya sea en formato impreso y/o digital.

\section{f. Financiación:}

Formas de financiación de la editorial con el cual puede subvencionar los costos asociados a sus proyectos editoriales.

\section{g. Unidad:}

Es el nivel de cohesión interna del catálogo, entendido como un sistema editorial.

\section{h. Congruencia:}

Porcentaje de relación e ilación conversacional con los otros títulos del catálogo, en tanto dispositivo editorial.

\section{i. Pertinencia al contexto:}

Nivel de consonancia de los contenidos de sus productos con las problemáticas y temáticas de la ciudad donde está asentada la editorial independiente.

\section{j. Géneros:}

Tipo de género al cual se suscriben los títulos del catálogo. También describe las apuestas estéticas y creativas de los textos.

\section{k. Géneros LIJ:}

Géneros que se suscriben del catálogo a lo infantil y lo juvenil.

\section{l. Mercado:}

Comportamiento frente al mercado y competidores locales. Propuesta de valor y elementos diferenciales frente a la oferta.

\section{m. Diseño editorial:}

Características del diseño y materialidad de los títulos del catálogo. También describe las apuestas estéticas visuales y creativas del libro objeto.

\section{n. Sitio web:}

Dirección online en la cual se encuentra la información de la editorial independiente.

Por su parte, las conversaciones con los editores privilegiaron el formato de entrevista semiestructurada, que permitieran la posibilidad de interactuar con ellos, escuchar sus percepciones frente a la industria, sus continuas quejas frente a las condiciones de participación en el mercado, sus anhelos de una integración y formación gremial consistente en a nivel local y regional. Lo que permite mejorar aspectos como la distribución y circulación de contenidos, a partir de la coedición, o la cesión de derechos, impresión local, impresión por demanda, acuerdos con librerías, bibliotecas e instituciones, entre otras estrategias.

\section{Resultados}

A través del análisis documental en papel y digital de los catálogos y con algunas entrevistas con editores, podemos socializar los siguientes resultados parciales:

\section{- Autorías y derechos de au- tor:}

La autoría es un tema que define la impronta de una editorial. Por ejemplo, en Babel se seleccionan autores que no han sido publicados o que está descatalogados. Mientras que en Ediciones de la Terraza apuestan a la publicación de poesía infantil. Tienen un catálogo que aparece online y se pueden descargar todos los libros en formato digital, lo cual plantea una discusión muy interesante, pues utilizan licencias Creative Commons. También, se evidencian muchas adaptaciones, algunas que surgen de un proceso no solo de traducción y adaptación a un lenguaje para un público infantil y juvenil, sino existen procesos de transducción cultural. Esto se observa en temáticas 
extranjeras adaptadas a nuevas producciones.

La transducción cultural se puede entender como el proceso que «sufre» un producto cultural que trasciende un mercado «original», y logra ir más allá del lugar en el cual fue concebido y gestado. (Uribe-Jongbloed y Espinosa-Medina, 2017).

\section{- Géneros y narrativas}

Si bien la industria editorial es un universo amplio, clasificar los géneros editoriales, literarios, textuales y narrativos, es materia de discusión. Aunque en los estudios generales de edición se usan las especialidades: libro escolar, libro infantil y juvenil, libro religioso, entre otros. Existen criterios organizadores de las obras, los cuales se pueden problematizar en su contenido y estructura. Para el caso de las editoriales independientes, identificamos que los géneros preferidos son el cuento, el libro silencioso y las ediciones que permiten un plus en el trabajo artesanal. Este punto se relaciona con el siguiente, $y$ es la construcción diseñística que teje profesionales dedicados al trabajo con la imagen y la composición visual.

\section{- Apuesta del diseño edito- rial}

El diseño editorial comprende una de las especialidades del Diseño Gráfico/Comunicación más heterodoxos en su constitución, pues se compone de saberes diferentes que provienen de distintas áreas de conocimiento y oficios. Principalmente, explora no solo la relación formal de composición de los artefactos editoriales, sino que indaga por la experiencia de lectura de las publicaciones. También, implica la pregunta sobre la dirección de arte y aspectos más técnicos, como el papel, los gramajes y el color.

Las variables que surgen de esta categoría tienen que ver con los formatos, las identidades editoriales, anatomías, tipografías, imágenes, composiciones y maquetaciones, las salidas de producción (impresión y/o dispositivos digitales), los tipos de encuadernación, estuches, troquelados y acabados especiales. Para ello, se tuvieron en cuenta las características de forma, color, textura, escala, movimiento, espacio, balance, simetría, asimetría, tensión, cierre, expresión, abstracción, tono, contraste, figura-fondo, encuadre, proporción, retícula que contenían los libros.

Para este caso, y de acuerdo con nuestro objeto de estudio, se encuentra que hay una apuesta a libros con técnica de encuadernación japonesa, sobrecubiertas en tela o detalles en las portadas. Por ejemplo, el libro Crack de Ediciones de la Terraza tiene un troquelado para romper la tapa del libro. Por su parte,
Babel trabaja con tapas duras, papeles gruesos y un uso armónico en los colores.

\section{- Estéticas y poéticas}

Los libros para niños y jóvenes amplían los horizontes de producción, hacia un lugar donde cualquier intervención en el objeto material, tendrá repercusiones en el régimen de lo sensible, lo que implica consecuencias en los aparatos perceptivos y cognitivos. Esto es clave para prefigurar oportunidades en el trabajo de las editoriales, y una posible proyección en un ambiente comunicativo, cada vez más complejo y saturado de medios, dispositivos y plataformas de contenidos.

Por lo tanto, los libros álbumes contienen una apuesta por las visualidades, textualidades, materialidades y la interacción entre estos elementos. La construcción gráfica y los diferentes usos del papel y la tinta, novedades en los sistemas técnicos de impresión, y la experimentación en soportes y materiales, ha brindado oportunidades editoriales, así como la masificación de los software de creación, lo que descentralizó la producción de los libros y contenidos mediáticos. Ana Garralón (2012) sostiene: "Los editores arriesgan y mucho. Eligen un libro, lo editan, lo imprimen, pagan a las imprentas y los anticipos a los autores, reciben los libros, los comercializa [...]". El trabajo del editor, 
entonces, es relevante, porque implica la primera lectura de un manuscrito, su aprobación o no y la dirección del proyecto editorial. Otra figura indispensable es la del diseñador y/o ilustrador, que decide cómo presentar ese libro y se encarga de aportar desde sus saberes en tres funciones: diseñar la experiencia de lectura, ajustar al dispositivo de salida los contenidos, y articular la palabra, imagen y materialidad como elementos importantes en el lenguaje editorial.

Finalmente, Barbi Couto sostiene:

[...] nosotros somos de la idea de que la ilustración tiene que estar, no es un adorno, no acompaña, no es de menor importancia, no es el que el autor sea el autor de los textos y el ilustrador lo pone bonito nada más, sino que para nosotros, los dos son autores cada uno desde su lugar.

La irrupción en el mercado de estas nuevas formas de concebir el libro, implican revisar teóricamente los fundamentos de construcción de libros y las redes culturales y económicas que se tejen, así como los roles y protagonismos de cada uno de los actores que constituye el equipo de trabajo.

\section{- Formas de financiamiento}

Los costos de edición son elevados, por lo tanto muchas editoriales se financian de manera creativa. Barbi Couto (Ediciones de la Terraza) sostiene que los financiamientos colectivos involucran un montón de gente en la concreción del proyecto, y así surgen «los libros con hincha$d a \gg$. Este proceso es diferente a la compra de un libro ya editado y seleccionado, porque involucra al lector desde el primer momento de producción: antes que el libro sea libro. Lo que genera una lógica muy diferente de los procesos de producción, circulación y consumo de los productos que confecciona la editorial.

En general, las editoriales independientes se caracterizan por realizar otro tipo de tareas y actividades para poder solventar los gastos, los cuales incluyen un variopinto portafolio de productos y/o servicios. Tanto Ediciones de la Terraza, como Siete Gatos ofrecen trabajos de asesoría editorial. Esta última, además comercializa agendas y cuadernos. Babel tiene una librería en Bogotá que vende libros y ofrece cursos de capacitación. De esta forma, vemos cómo se relaciona con el punto de las políticas públicas, tratado en el primer acápite de la ponencia, donde las necesidades económicas no pueden ser solventadas con las ganancias de las editoriales, y, por lo tanto, se apela a otro tipo de ingreso. Con respecto a la política de cultura libre, Babel promueve una biblioteca que habilita a los niños a llevarse libros, y ediciones de la terraza tiene una promoción de cultura abierta.

\section{Conclusiones}

Las conclusiones que surgen del análisis y la revisión de los catálogos de las editoriales independientes bogotanas (Colombia) y cordobesas (Argentina), esbozan la repercusión de las editoriales independientes en los ecosistemas culturales latinoamericanos. Esto puede analizarse en dos grandes esferas imbricadas: una económica y otra cultural.

Con respecto a la económica, es evidente la búsqueda de alternativas de financiamiento. Así, en un mismo emprendimiento conviven diversas formas de apostar por su sostenimiento en una economía frágil y que fácilmente puede desestabilizarse. Algunos diversifican, a través de líneas de negocio como venta de libros, dictan cursos y talleres, ofertan servicios editoriales y de impresión, entre otros. Parecería que la premisa es sobrevivir en el mercado con agilidad y creatividad. Una de las evidentes estrategias es la inclusión de formatos digitales, no solo para la promoción de la editorial, a través de sitios web, páginas y redes sociales, sino también la participación en espacios de micromecenazgo y crowdfunding, lo que crea un vínculo con los lectores-patrocinadores muy diferente al convencional.

La gran incertidumbre financiera provoca fuertes repercusiones en lógicas del trabajo deslocalizado, lo que permite nuevas formas 
de organización de las labores propias de un proyecto editorial. Esto ha traído la posibilidad de configurar equipos editoriales con personas de diferentes nacionalidades, entre ellos europeos, asiáticos, latinoamericanos.

En los aspectos culturales, observamos que las lógicas mercantiles impactan en dos puntos fuertes de las editoriales. El primero es la globalización de relatos, esto ha traído en las narrativas y configuraciones cada vez más orientadas a una deslo- calización que permita migrar los contenidos fácilmente a diferentes países y regiones. Para poder comercializar el producto en muchos casos, es necesario contar con «historias universales» que puedan ser comprendidas por cualquier lector, sin importar su procedencia. Allí, vemos una transnacionalidad de narrativas y relatos. Esto, para competir en un mercado global, es una de las constantes, pues en muchos casos no retoman relatos costumbristas (cuestiones culturales propias de la ciudad) y modismos (jergas).
El segundo es la fuerte apuesta por el libro objeto, la materialidad de los libros es muy importante, en el mundo de lo «independiente», porque implica la diferencia y la venta. Por tanto, es muy notorio el cuidado que existe sobre la apuesta gráfica, la experimentación de materiales, sustratos, formatos, tipos de encuadernación y técnicas de ilustración. Lo que genera un valor estético y simbólico muy importante para el libro como objeto cultural.

\section{Referencias}

Bajour, C., \& Carranza, M. (2003). El libro álbum en Argentina. Imaginaria (107). Recuperado el 20 de agosto de 2008, de https://www.imaginaria.com.ar/10/7/libroalbum.htm

Garralón, A. (2012). ¡Urgente! Se buscan escritores de literatura infantil. Anatarambana literatura infantil. Recuperado el 20 de agosto de 2008, de http://anatarambana.blogspot. com.ar/2012/07/urgente-se-buscan-escritores-de.html

López, H., \& Malumián, V. (2016). Independientes, ¿de qué? Hablan los editores de América Latina. México: Fondo de Cultura Económica.

Menéndez, L. (2006). ¿Qué cosas nos trajo el tiempo? Viejas y nuevas tendencias en las ilustraciones de libros para niños. Páginas de guarda n. ${ }^{\circ} 1$.

Schritter, I. (2011) La otra lectura: la ilustración en los libros para niños. Buenos Aires: Lugar editorial.

Uribe-Jongbloed, E., y Espinosa-Medina, H. (2017). Introducción a la transducción cultural. Palabra clave, 20 (3). Recuperado de https://palabraclave.unisabana.edu.co/index.php/palabraclave/ article/view/7635

Zaid, G. (2010). Los demasiados libros. Barcelona: Debolsillo.

Zapata, D. (2014). Una región de lectores que crece. Análisis comparado de planes nacionales de lectura en Iberoamérica 2013. Bogotá: CERLALC-UNESCO. 